\title{
The Precursor of Loneliness in Sports Sciences Students: Psychological Resilience
}

\section{Serhat Turan ${ }^{*}$, Ahmet Dönmez ${ }^{2}$, Cengiz Baykara $^{2}$, Fikret Soyer ${ }^{1}$}

${ }^{1}$ Faculty of Sports Sciences, Balikesir University, Balikesir, Turkey

${ }^{2}$ Graduate Education Institute, Department of Physical Education and Sport, Sakarya University of Applied Sciences,

Study Area: Sakarya, Turkey

Coordinates: $40^{\circ} 41^{\prime} 50^{\prime \prime} \mathrm{N}_{30}^{\circ} 27^{\prime} 24$ " E

Key words: Positive psychology, Sports psychology

\section{Abstract}

A total of 375 sports sciences students, 95 of whom are women, 280 of whom are men, selected by convenience sampling method. The study was designed with the correlational survey model. Research data were collected using the "Personal Information Form", "UCLA Loneliness Scale (ULS-8)" and "Brief Psychological Resilience Scale". The data were analyzed using Pearson correlation analysis in the SPSS program and path analysis technique within the framework of structural equation modelling in the AMOS program. A moderate negative relationship was found between loneliness and psychological resilience. In addition, it was found that psychological resilience significantly predicted loneliness. These results indicate that while aiming to reduce the loneliness levels of sports science students, their psychological resilience should also be taken intoaccount.

refers to internal factors such as personality and psychological factors (Singh \& Misra, 2009). This study focused on psychological resilience, which is one of the internal factors.

Psychological resilience, which is an important part of positive psychology (Huang et al., 2020), has become a concept that arouses significant scientific interest in the last three decades (Van Der Meulen et al., 2019). Resilience is the concept that reveals the interaction between internal and external protection and risk processes (Rutter, 1985, 2002), which includes the state of being free from negative experiences (Garmezy, 1991; Norris et al., 2009). Psychological resilience has aroused curiosity in higher education environments because of its protective role against stress and improved academic performance (Allan et al., 2014; Howell \& Miller-Graff, 2014). Besides, many studies in the literature revealed that psychological resilience is related to many psychological factors such as self-esteem, emotional flexibility, positive and negative emotion, emotion regulation, inhibitory control, and others (Burns et al., 2011; Curtis \& Cicchetti, 2007; Liu et al., 2012; Yu \& Zhang, 2007). In addition to these, it provides an important contribution to the development of psychological resilience, happiness, and life satisfaction (Gable \& Haidt, 2005; Hu et al., 2015). Psychological resilience, which directly affects many psychological and internal factors, may contribute to a decrease in the feeling 
of loneliness in the individual. The feeling of loneliness, which is positively related to negative emotions and is a risk factor, may tend to decrease with the introduction of psychological resilience, which is an important protective factor. As a matter of fact, it has been revealed in the related literature that individuals with high psychological resilience express themselves less alone and hopeless (Rew et al., 2001). In the context of the studies examined in the literature and the information given above, it was investigated in this study whether psychological resilience predicts loneliness or not.

\section{Materials and Methods:}

The research has been designed by using the "correlational survey model" in terms of the purpose and scope of the research. The correlational survey model is a "research model aiming to determine the existence and/or degree of change between two or more variables" (Karasar, 2018).

The research group consists of 375 students, 95 of whom are women, 280 of whom are men, selected by convenience sampling method enrolled in the undergraduate program of the Faculty of Sport Sciences of Sakarya Applied Sciences University in the fall semester of the 2019-2020 academic year. The average age of the research group is $21.53 \pm 2.91$.

The data of the study were collected personally from students who wanted to participate voluntarily in the fall semester of the 2019-2020 academic year, after the researchers gave verbal and written explanations to the students in the classroom environment between December 2 and December 20, 2019.

"Personal Information Form", "UCLA Loneliness Scale (ULS-8)" and "Psychological Resilience Scale" were used as measurement tools in the study. Detailed information about measurement tools is explained below. $\mathrm{T} \mathrm{h}$ e demographic information form used in the study, it is aimed to reach information such as gender, age, and sports years of the students.

UCLA Loneliness Scale (ULS-8) used in the research was developed by Russell et al., (1978). It was adapted to Turkish by Dogan et al., (2011). The measuring tool is of 8 items, 4 pointslikert type. Higher scores on the scale indicate higher loneliness. The Cronbach Alpha coefficient of the scale was found to be .72 (Dogan et al., 2011). In this study, the Cronbach Alpha (a) internal consistency coefficient of the loneliness scale was determined as .82.

The Brief Psychological Resilience Scale (BPRS) used in the research was developed by Smith et al., (2008) and adapted into Turkish by Dogan (2015). The measuring tool is of 6 items 5 pointslikert type. High scores from the scale indicate high psychological resilience. The Cronbach Alpha coefficient of the scale was found to be 83 (Dogan, 2015). In this study, the Cronbach Alpha (a) internal consistency coefficient of the psychological resilience scale was determined as .69.
The data collected from the students were analyzed in terms of erroneous value, outlier, and normality, and it was determined that the data were suitable for normal distribution. The data were analyzed using Pearson correlation analysis in the SPSS program and path analysis technique within the framework of structural equation modeling in the AMOS program.

\section{Results:}

It has been observed that it is obtained within the limits as $\mathrm{CMIN}=291.328 ; \quad \mathrm{DF}=75 . \quad \mathrm{p}<.001 ; \quad \mathrm{CMIN} / \mathrm{DF}=3.884$; RMSEA=.088.; $\mathrm{GFI}=.889 ; \mathrm{CFI}=.865$ according to the results obtained in the structural model. the model fit index values are determined.

Table 1. Examination of the structural equation model

\begin{tabular}{|c|c|c|c|c|c|c|c|}
\hline Model Item & Path & Factor & ßo & $\beta_{1}$ & S.E. & C.R. & $\mathrm{p}$ \\
\hline Lon. 1 & $<---$ & Lon. & 0.595 & 0.63 & $0.05^{8}$ & 10.824 & $<0.001$ \\
\hline Lon. 2 & $<---$ & Lon. & 0.572 & 0.585 & 0.056 & 10.382 & $<0.001$ \\
\hline Lon. 3 & $<---$ & Lon. & 0.232 & 0.266 & 0.064 & 4.177 & $<0.001$ \\
\hline Lon. 4 & $<---$ & Lon. & 0.781 & 0.845 & 0.059 & 14.212 & $<0.001$ \\
\hline Lon. 5 & $<---$ & Lon. & 0.813 & 1.091 & 0.074 & 14.715 & $<0.001$ \\
\hline Lon. 6 & $<---$ & Lon. & 0.427 & 0.502 & 0.065 & 7.735 & $<0.001$ \\
\hline Lon. 7 & $<---$ & Lon. & 0.598 & 0.753 & 0.069 & 10.897 & $<0.001$ \\
\hline Lon. 8 & $<---$ & Lon. & 0.744 & 1 & & & \\
\hline Psy. res. 1 & $<---$ & Psy. res. & 0.554 & 0.637 & 0.075 & 8.453 & $<0.001$ \\
\hline Psy. res. 2 & $<---$ & Psy. res. & 0.446 & 0.565 & 0.08 & 7.064 & $<0.001$ \\
\hline Psy. res. 3 & $<---$ & Psy. res. & 0.405 & $0.5^{2}$ & 0.08 & 6.485 & $<0.001$ \\
\hline Psy. res. 4 & $<---$ & Psy. res. & 0.623 & 0.798 & 0.087 & 9.173 & $<0.001$ \\
\hline Psy. res. 5 & $<---$ & Psy. res. & 0.374 & 0.471 & 0.078 & 6.021 & $<0.001$ \\
\hline Psy. res. 6 & $<---$ & Psy. res. & 0.731 & 1 & & & \\
\hline \multicolumn{8}{|c|}{ Structural Equation Model } \\
\hline Lon. & $<---$ & Psy. res. & -.368 & -0.32 & 0.06 & $-5 \cdot 368$ & $<0.001$ \\
\hline
\end{tabular}

Lon- Loneliness; Psy res.- psychological resilience

ßo: Standard Path Coefficients; ß1: Non-StandardPath Coefficients

Data analysis was analyzed with IBM AMOS V25. As a first step, measurement models of the dimensions are evaluated. It has been observed that it is obtained within the limits as $C M I N=291.328 ; D F=75 . \quad p<.001$; $\mathrm{CMIN} / \mathrm{DF}=3.884 ; \mathrm{RMSEA}=.088 ; \mathrm{GFI}=.889 ; \mathrm{CFI}=.865$ according to the results obtained in the structural model. the model fit index values are determined. Also all path coefficients were found to be statistically significant. The path coefficient between psychological resilience and loneliness in SEM was found to be statistically significant $\left(ß_{1}=-0.32 . p<.001\right)$.

\section{Discussion:}

As a result of this study, it was found that there is a negative and significant relationship between psychological resilience and loneliness $(\mathrm{r}=-.336, \mathrm{p}<.001)$. Also, the path coefficient between psychological resilience and loneliness was found to be statistically significant.

When the literature was searched, some studies were found that obtained similar results to the current research results. Tuğral (2020) found a negative, low, and significant relationship between psychological resilience and 
loneliness. Also, he concluded that loneliness is a meaningful explanation of $7.5 \%$ of psychological resilience. Kiliç (2014) found that as the psychological resilience of university students increased, their loneliness decreased. Yakici (2017) found a moderately significant negative correlation between psychological resilience and loneliness in his study on adult individuals. They also found that life satisfaction and loneliness variables explain $38 \%$ of the total variance in psychological resilience scores. Altundağ (2013) stated on adolescents whose parents divorced, life satisfaction, and loneliness together affect psychological resilience by $84 \%$. Erözkan (2009) in his study on high school students; found that shyness, social anxiety, and psychological resilience were predictors of loneliness. Güloğlu \& Karaırmak (2010) reported on university students that a negative and significant relationship between loneliness and psychological resilience. Yardimci et al., (2017) found that the relationship between loneliness and mental endurance in sports was negative and significant in their studies. Perron et al., (2014) found a negative and significant relationship between loneliness and resilience in their study on homeless youth. However, taking psychological distress into account, it revealed that loneliness is not significantly associated with resilience among homeless youth. Rew et al., (2001) found in their study that loneliness is significantly associated with psychological resilience. Gerino et al., (2017) found the mediating effect of both endurance and mental health between loneliness and mental and physical quality of life.

When the findings obtained in this study and the results of the studies in the literature were examined, it was seen that psychological resilience had a significant effect on loneliness and the relationship between them was negative. Among the reasons for this situation, it is thought that protective factors have an important effect on psychological resilience (Gürgan, 2006; Masten, 1994; Masten \& Reed, 2002). School support, which is one of the protective factors, is one of the most important factors affecting the psychological resilience of the individual (Werner, 2007). The individual spends a large part of his/her daily life at the school, and the school environment and school staff protect the individuals from the damaging elements of the outside world by assuming the protective role (Wright et al., 2013). Therefore, the individual who realizes his psychological strength can lead a social life away from loneliness. Fry \& Debats (2010) determined that people with high self-efficacy and mental resilience can mobilize emotional and psychological resources to face the stressful elements of their lives. As a result, considering that individuals' school environments are a part of their living space, this is thought to be a reason for the result obtained in the study.

Also, expressed as internal and external protective factors of psychological resilience; It is thought that variables such as peer support, empathy, and willingness to fight to prevent loneliness from occurring, and thus affect the formation of a negative relationship. Again, it can be stated that having strong social relations with individuals with high psychological resilience (Gürgan, 2006) will prevent individuals from experiencing loneliness. Adams et al., (2004) support ourview by finding that individuals with a less comprehensive social network are more lonely.

The research was carried out only with university students studying at the sports science faculty. It is thought that conducting the study at different educational levels, different branches, and individuals with different sports backgrounds will help to better understand the relationship between psychological resilience and loneliness. Also, it is thought that working with people who have been doing sports for a long time and sedentary individuals will enable the mediation effect of sports to be measured.

\section{References:}

Adams, K.B., Sanders, S. \& Auth, E.A. (2004): Loneliness and depression in independent living retirement communities: Risk and resilience factors. Aging Ment. Health, 8(6):475485.

Allan, J.F., McKenna, J. \& Dominey, S. (2014): Degrees of resilience: profiling psychological resilience and prospective academic achievement in university inductees. Bri. J. Guid. Counsel., $42(1): 9-25$.

Altundag, Y. (2013): Life satisfaction and loneliness as predictive variables of resilience in adolescent with divorced parents. (Master Thesis). AbantIzzet Baysal University, Institute of Educational Sciences, Bolu.

Anderson, C.A. \& Harvey, R.J. (1988): Brief report: Discriminating between problems in living: An examination of measures of depression, loneliness, shyness, and social anxiety. J. Soc. Clin. Psychol., 6(3-4):482-491.

Burns, R.A., Anstey, K.J. \& Windsor, T.D. (2011): Subjective wellbeing mediates the effects of resilience and mastery on depression and anxiety in a large community sample of young and middle-aged adults. Aus. $N$ Zealand I. Psychiat., 45(3):240-248.

Cacioppo, J.T. \& Patrick, W. (2008): Loneliness: Human nature and the need for social connection. Pub. by: WW Norton \& Company.

Cacioppo, J.T., Hawkley, L.C. \& Patrick (2011): Lonely planet. Pub. by: RSAJ., 157(Autumn).

Cacioppo, J.T., Hawkley, L.C. \& Thisted, R.A. (2010): Perceived social isolation makes me sad: 5-year cross-lagged analyses of loneliness and depressive symptomatology in the Chicago Health, Aging, and Social Relations Study. Psychol. Aging, 25(2):453.

Curtis, W.J. \& Cicchetti, D. (2007): Emotion and resilience: A multilevel investigation of hemispheric electroencephalogram asymmetry and emotion regulation in maltreated and nonmaltreated children. Devel. Psychopathol., 19(3):811-840. 
Dogan, T. (2015): Adaptation of the Brief Resilience Scale into Turkish: A validity and reliability study. J. Happiness $\mathcal{E}$ WellBeing, 3(1):93-102.

Dogan, T., Çötok, N.A. \& Tekin, E.G. (2011): Reliability and validity of the Turkish Version of the UCLA Loneliness Scale (ULS-8) among university students. Proc. Soc.. Behav. Sci., 15:20582062.

Erözkan, A. (2009): Predictors of loneliness in adolescents. Pri. Edu. Online, 8(3):809-819.

Fry, P.S. \& Debats, D.L. (2010): Sources of human life-strengths, resilience, and health, in eds New Frontiers in Resilient Aging: Life-Strengths and Well-Being in Late Life, eds P. S. Fry and C. L. M. Keyes Pub. by: (Cambridge: Cambridge University Press).

Gable, S.L. \& Haidt, J. (2005): What (and why) is positive psychology? Rev. Gen.Psychol., 9(2):103-110.

Garmezy, N. (1991): Resilience in children's adaptation to negative life events and stressed environments. Pediat. Ann., 20(9):459-466.

Gerino, E., Rollè, L., Sechi, C. \& Brustia, P. (2017): Loneliness, resilience, mental health, and quality of life in old age: A structural equation model. Front. Psychol., 8(2003).

Green, B.H., Copeland, J.R.M., Dewey, M.E., Sharma, V., Saunders, P.A., Davidson, I.A., Sullivan, C. \& McWilliam, C. (1992): Risk factors for depression in elderly people: a prospective study. Acta. Psychiat. Scand., 86(3):213-217.

Güloglu, B. \& Karairmak, Ö. (2010): Self-esteem and resilience as the predictors of loneliness among university students. Ege. J. Edu.,11(2):73-88.

Gürgan, U. (2006): The Effect of the group program of resiliency level of university students. ( $\mathrm{PhD}$ Thesis). Ankara University, Institute of Educational Sciences, Ankara.

Hawkley, L.C. \& Cacioppo, J.T. (2010): Loneliness matters: A theoretical and empirical review of consequences and mechanisms. Ann.. Behav. Med., 40(2):218-227.

Holt-Lunstad, J., Smith, T.B., Baker, M., Harris, T. \& Stephenson, D. (2015): Loneliness and social isolation as risk factors for mortality: a meta-analytic review. Persp. Psychol. Sci., 10(2):227-237.

Howell, K.H. \& Miller-Graff, L.E. (2014): Protective factors associated with resilient functioning in young adulthood after childhood exposure to violence. Child Abuse Neglect, 38(12):1985-1994.

Hu, T., Zhang, D. \& Wang, J. (2015): A meta-analysis of the trait resilience and mental health. Personal. Indiv. Diff.,76:18-27.

Huang, Y., Wu, R., Wu, J., Yang, Q., Zheng, S. \& Wu, K. (2020): Psychological resilience, self-acceptance, perceived social support and their associations with mental health of incarcerated offenders in China. Asian J. Psychiat., 102166.

Karasar, N. (2018): Scientific Research Methods: Concepts, Principles and Techniques. (32nd Baski). Pub. by:Nobel Publishing, Ankara.

Kiliç, S.D. (2014): Analysis on the loniness and psychological resilience of undergraduate student. (Master Thesis). Ataturk University, Institute of Educational Sciences, Erzurum.
Liu, Y., Wang, Z.H. \& Li, Z.G. (2012): Affective mediators of the influence of neuroticism and resilience on life satisfaction. Personal. Indiv. Diff., 52(7):833-838.

Luo, Y. \& Waite, L.J. (2014): Loneliness and mortality among older adults in China. L. Gerontol. Seri. B: Psychol. Sci. Social Sci., 69(4):633-645.

Masten, A.S. (1994): Resilience in individual development: Successful adaptation despite risk and adversity: Challenges and prospects, pp. 3-25. In: Educational resilience in inner city America: Challenges and Prospects. Pub. by: Lawrence Erlbaum.

Masten, A.S. \& Reed, M.G.J. (2002): Resilience in development. Pub. by: Handbook of Positive Psychology.

Matthews, T., Danese, A., Gregory, A.M., Caspi, A., Moffitt, T.E. \& Arseneault, L. (2017): Sleeping with one eye open: loneliness and sleep quality in young adults. Psychol. Med., 47(12):21772186.

Mushtaq, R., Shoib, S., Shah, T. \& Mushtaq, S. (2014): Relationship between loneliness, psychiatric disorders and physical health? A review on the psychological aspects of loneliness. L. Clinic. Diagnostic Res., 8(9):WEo1.

Norris, F.H., Tracy, M. \& Galea, S. (2009): Looking for resilience: Understanding the longitudinal trajectories of responses to stress. Social Sci. Med., 68(12):2190-2198.

Peplau, L. \& Perlman, D. (1982): Perspectives on loneliness. In: Loneliness: A sourcebook of current theory, research and therapy. Pub. by: John Wiley, USA.

Perlman, D. \& Peplau, L.A. (1981): Toward a social psychology of loneliness. Personal. Relation., 3:31-56.

Perron, J.L., Cleverley, K. \& Kidd, S.A. (2014): Resilience, loneliness, and psychological distress among homeless youth. Arch. Psychiat. Nurs., 28(4):226-229.

Pieters, R. (2013): Bidirectional dynamics of materialism and loneliness: Not just a vicious cycle. J. Cons. Res., 40(4):615-631.

Prince, M.J., Harwood, R.H., Blizard, R.A., Thomas, A. \& Mann, A.H. (1997): Social support deficits, loneliness and life events as risk factors for depression in old age. Gospel Oak Proj. VI. Psychol. Med., 27(2):323-332.

Rew, L., Taylor-Seehafer, M., Thomas, N.Y. \& Yockey, R.D. (2001): Correlates of resilience in homeless adolescents. L. Nurs. Schol.,33(1):33-40.

Russell, D., Peplau, L.A. \& Ferguson, M.L. (1978): Developing a measure of loneliness. J. Personal. Asses., 42(3):290-294.

Rutter, M. (2002): Resilience concepts and findings: implications for family therapy. J. Fam. Ther., 21, 119-144.

Rutter, M. (1985): Resilience in the face of adversity: protective factors and resistance to psychiatric disorder. Br. J. Psychiat., 147:598-611.

Singh, A. \& Misra, N. (2009): Loneliness, depression and sociability in old age. Indus. Psychiat. J., 18(1):51.

Smith, B.W., Dalen, J., Wiggins, K., Tooley, E., Christopher, P. \& Bernard, J. (2008): The brief resilience scale: assessing the ability to bounce back. Int.J. Behav. Med., 15(3):194-200.

Stravynski, A. \& Boyer, R. (2001): Loneliness in relation to suicide ideation and parasuicide: A population-wide study. Suicide 


\section{ORIGINAL ARTICLE}

Life-threaten. Behav., 31(1):32-40.

Teo, A.R., Choi, H. \& Valenstein, M. (2013): Social relationships and depression: ten-year follow-up from a nationally representative study. PloS one, 8(4):e62396.

Tugral, R. (2020): Loneliness, psychological resilience, social support and social appearance anxiety in adolescents. (Master Thesis). Nisantasi University, Social Sciences Institute, Istanbul.

Van Der Meulen, E., van Veldhoven, M.J. \& Van Der Velden, P.G. (2019): Stability of psychological resilience of police officers: A three-wave latent class analysis. Personal. Indiv. Diff., 144:120-124.

Vasileiou, K., Barnett, J., Barreto, M., Vines, J., Atkinson, M., Long, K., Bakewell, L., Lawson, S. \& Wilson, M. (2019): Coping with loneliness at University: A qualitative interview study with students in the UK. Mental Health Prevent., 13:21-30.

Wee, L.E., Tsang, T.Y.Y., Yi, H., Toh, S.A., Lee, G L., Yee, J., Lee, S., Oen, K. \&Koh, G.C.H. (2019): Loneliness amongst lowsocioeconomic status elderly Singaporeans and its association with perceptions of the neighbourhood environment. Int.J. Envi. Res. Pub. Health, 16(6):967.
Ambient Science, 2020: Vol. 07(Sp1); 120-124 DOI:10.21276/ambi.2020.07.sp1.oa13

Werner, E. (2007): How children become resilient: Observations and cautions. In N. Henderson (Ed.), Resiliency in Action: Practical Ideas for Overcoming Risks and Building Strengths in Youth, Families, and Communities. Pub. by: Solvang, CA: Resiliency In Action.

Wright, M.O.D., Masten, A.S. \& Narayan, A.J. (2013): Resilience processes in development: Four waves of research on positive adaptation in the context of adversity. In Handbook of Resilience in Children. Pub. by: Springer, Boston, MA.

Yakici, E.G. (2017): Life satisfaction and loneliness as preditor variables in emerging adulthood's psychological endurance levels.(Master Thesis). Necmettin Erbakan University, Institute of Educational Sciences, Konya.

Yardimci, A., Sadik, R. \& Karda?, N.T. (2017): The relationship between loneliness levels and sport mental resistance levels of American football players. J. Sport Sci. Res., 2(2):79-90.

Yu, X. \& Zhang, J. (2007): Factor analysis and psychometric evaluation of the Connor-Davidson Resilience Scale (CDRISC) with Chinese people. Soc. Behav. Personal.: Int. J., 35(1):19-30. 